\title{
Structural modifications of lanthanum silicate oxyapatite exposed to high water pressure
}

\author{
Aénor Pons ${ }^{\text {a }}$, Jenny Jouin ${ }^{\mathrm{a}}$, Maggy Colas ${ }^{\mathrm{a}}$, Emilie Béchade ${ }^{\mathrm{a} *}$, Pierre-Marie Geffroy ${ }^{\mathrm{a}}$, Mikhail \\ Smirnov $^{\mathrm{f}}$, Olivier Masson ${ }^{\mathrm{a}}$, Philippe Thomas ${ }^{\mathrm{a}}$, Isao Kagomiya ${ }^{\mathrm{b}}$, Toru Asaka ${ }^{\mathrm{c}}$, Koichiro \\ Fukuda $^{\mathrm{c}}$, Aneta Slodczyk $^{\mathrm{d}}{ }^{\mathrm{e}}$, Philippe Colomban ${ }^{\mathrm{de}}$ \\ ${ }^{a}$ Science des Procédés Céramiques et de Traitements de Surface (SPCTS), CNRS UMR 7315, Centre Européen \\ de la Céramique, 12 rue Atlantis, 87068 LIMOGES Cedex, France \\ ${ }^{\mathrm{b}}$ Department of Materials Science and Engineering, Nagoya Institute of Technology, Nagoya 466-8555, Japan \\ ${ }^{\mathrm{c}}$ Department of Environmental and Materials Engineering, Nagoya Institute of Technology, Nagoya 466-8555, \\ Japan \\ ${ }^{d}$ Sorbonne Universités, UPMC Univ Paris 06, UMR 8233, 4 Place Jussieu, 75005 Paris, France \\ ${ }^{e}$ CNRS-IP2CT, UMR 8233, MONARIS, 4 Place Jussieu, 75005 Paris, France \\ ${ }^{f}$ Department of Physics, Saint-Petersburg State University, 198504 Petrodvorets, Russia
}

\begin{abstract}
Lanthanum silicate oxyapatite samples of initial compositions $\mathrm{La}_{9.13}\left(\mathrm{SiO}_{4}\right)_{6} \mathrm{O}_{1.7}$, $\mathrm{La}_{9.33}\left(\mathrm{SiO}_{4}\right)_{6} \mathrm{O}_{2}$ and $\mathrm{La}_{9.60}\left(\mathrm{SiO}_{4}\right)_{6} \mathrm{O}_{2.4}$ were exposed to high water pressure in autoclave, in order to study the effects of initial oxygen stoichiometry and treatment duration on the protonation of these materials. TG analyses, done on very dense pellets (over 98.5\%), showed that protonic species from the water vapour were successfully introduced into the bulk of the material. The sample showing the higher mass change after treatment was the one of initial composition $\mathrm{La}_{9.60}\left(\mathrm{SiO}_{4}\right)_{6} \mathrm{O}_{2.4}$, after 84 hours of treatment at $550^{\circ} \mathrm{C}$ under 40 bars water pressure. The mass loss observed above $600^{\circ} \mathrm{C}$ (bulk species) is about $0.2 \%$ which is in good agreement with observed results on TG curves recorded on very dense ( $99 \%)$ perovskite pellets (under He atmosphere and for approximate duration times). Furthermore, it was shown that the mass loss increases when protonation time rises $(0.66 \%$ for $408 \mathrm{~h})$, with a time limit beyond which the microstructure of the oxyapatite is no more stable (between 84 and 408h).

Rietveld refinement of the cell parameters and structural study by Raman spectroscopy presented some structural modifications (especially on La-O5 (channel) bonds) which could be linked to the incorporation of protonic species. Indeed, it was shown that high water pressure treatment induced an increase of the cell volume (V 597.69 A to be compared with 587.69 A
\end{abstract}


for non-protonated La960) related to an increase of the a and b lattice parameters and an enlargement of the characteristic channels of oxyapatite.

Keywords: oxyapatite; powders solid-state reaction; fuel cells; SOFC; protonation; structure

*Corresponding author: $\quad$ emilie.bechade@unilim.fr 


\section{Introduction}

The development of environment-friendly electrochemical applications and clean energy conversion systems, such as Solid Oxide Fuel Cells (SOFC), is nowadays attracting a great scientific interest $\left[{ }^{1,2}\right]$.The most common material used as solid electrolyte in SOFC is oxide ion conducting yttria-stabilized zirconia (YSZ) $\left.{ }^{2,3}\right]$. However, current research aims to decrease the working temperature of SOFC down to intermediate temperatures $\left(600-800^{\circ} \mathrm{C}\right)$ by using new oxide ion conductors with equivalent conductivity values than $\mathrm{YSZ}$ at $1000^{\circ} \mathrm{C}$ (above $0.1{\mathrm{~S} . \mathrm{cm}^{-1}}^{-1}$. Apatite-type lanthanum silicates of general formula $\mathrm{La}_{9.33+\mathrm{x}}\left(\mathrm{SiO}_{4}\right)_{6} \mathrm{O}_{2+3 \mathrm{x} / 2}$, found by Nakayama and al. $\left[^{4,5}\right]$, are one of the most promising oxide ion conductors for application as electrolyte in Intermediate-Temperature SOFC (IT-SOFC) $\left[^{5,6,7,8,9}\right]$. Their structure is based on a 3-dimensional organization of isolated silica tetrahedral and forms large lanthanum oxide tunnels oriented along the c-axis $\left[^{10,11,12}\right]$. Such a structure can explain that oxyapatites exhibit high anisotropic conductivity in the c direction, which is increased by the incorporation of interstitial oxygen inside the large tunnels (formula with $x>0$ ) $[6,7,8,9,13,14,15]$. The reactive diffusion method reported by Fukuda and al. $\left[^{6,7,11,16}\right]$ allows the elaboration of highly c-axis oriented lanthanum silicate apatite polycrystal material which exhibited high oxide ion conductivity values : $2.4 \times 10^{-3}{\mathrm{~S} . \mathrm{cm}^{-1}}^{-1} 2.39 \times 10^{-2}{\mathrm{~S} . \mathrm{cm}^{-1}}$ from 573 to $973 \mathrm{~K}$ with an activation energy of $0.35 \mathrm{eV}$ (in agreement with the calculated migration energy of $0.32 \mathrm{eV}$ linked to an original push-pull mechanism ${ }^{[14,17]}$ ).

Recent studies $\left[{ }^{18},{ }^{19},{ }^{20}\right]$ show that the apatite structure could also enable the incorporation and conduction of protons. Thus, oxyapatite might be a new promising proton-conducting material for application as electrolyte in Proton Conducting SOFC (PC-SOFC) $\left.{ }^{21}{ }^{22}\right]$, which has the advantage of operating at lower temperatures $\left(400-600^{\circ} \mathrm{C}\right)$. Contrary to anionic conduction, in the case of protonic conduction, the electrolyte material requires a moisturizing step, in order to enable the insertion and conduction of protons, which are not usually present in the material structure. The first works about the protonation of oxides, on the 1950s, has been performed on the reduction of $\mathrm{ZnO}$ materials which have shown the incorporation of protons in the oxide lattice $\left[{ }^{23}\right]$. Most studies, especially about $(\mathrm{Ba}, \mathrm{Sr})(\mathrm{Zr}, \mathrm{Ce}, \mathrm{Ti}, \mathrm{Y}) \mathrm{O}_{3-\delta}$ oxygen deficient perovskite materials $\left[{ }^{24}, 25,26,27,28,{ }^{20},{ }^{30}\right]$ shows the complexity of water/proton insertion mechanism (called protonation) and the competition between surface and volume protonic species during the protonation step. Colomban et al. $\left[^{25,26,27,28}\right]$ found out that the pure and dense samples of $(\mathrm{Ba}, \mathrm{Sr})(\mathrm{Zr}, \mathrm{Ce}, \mathrm{Ti}, \mathrm{Y}) \mathrm{O}_{3-\delta}$ perovskites, under high pressures of decarbonated water and at high temperature (using an autoclave), promotes the creation of 
volume protonic species, instead of surface water and surface hydroxycarbonate-type species (which must be avoided in the case of electrolyte materials of PC-SOFC).

Reactions (1a) $\left[^{31,32,33}\right]$ and (1b) $\left[{ }^{33,34,35,36}\right]$ are the main protonation reactions given in literature to describe the incorporation of water, generally into oxygen-deficient perovskites ceramics.

$$
\begin{aligned}
& H_{2} O_{(g)}+V_{O}^{\bullet \bullet} \leftrightarrow 2 H_{i}^{\bullet}+O_{O} \\
& H_{2} O_{(g)}+V_{O}^{\bullet \bullet}+O_{O} \leftrightarrow 2\left(O H_{O}^{\bullet}\right)
\end{aligned}
$$

They lead to a global reaction (1c) as given by Deng et al. ${ }^{37}$

$$
\mathrm{H}_{2} \mathrm{O}_{(g)}+\mathrm{V}_{O}^{\bullet}+\mathrm{O}_{O} \leftrightarrow 2 \mathrm{H} \cdots \mathrm{O}_{O}^{\bullet}
$$

However, this last assumption is not always confirmed and it is not trivial to determine the nature or position of protons in oxides $\left[{ }^{24,27,33,38,39}\right]$. Also, the dissociation mechanism of water molecules has not yet been well understood in the literature ${ }^{[27]}$.

In the case of apatite material, which can present oxygen interstitials or vacancies, three other protonation reactions can be suggested $\left[{ }^{19,20}\right]$ involving oxygen interstitial:

$$
\begin{aligned}
& H_{2} O_{(g)}+O_{O} \leftrightarrow O H_{O}^{\bullet}+O H_{i}^{\prime} \\
& H_{2} O_{(g)}+O_{i}^{\prime \prime} \leftrightarrow 2 O H_{i}^{\prime} \\
& H_{2} O_{(g)}+2 O_{O} \leftrightarrow 2 O H_{O}^{\bullet}+O_{i}^{\prime \prime}
\end{aligned}
$$

It is possible to evaluate the amount of water dissociated into the host structure of the material by TGA, which is the most common method to measure the proton amount in oxides $\left[{ }^{25,26,27,29,40}\right]$. The total weight loss observed can reveal the departure of free water, chemically bounded water and hydroxides below $600^{\circ} \mathrm{C}$, and the presence of "protonic" species inside the host structure (denoted as bulk "protonic" species) above this temperature. However, the TGA analysis does not allow determining the $\mathrm{H}$ content as well as the neutron measurements does $[25,26,27,29]$. The variation of mass linked to the protonation or the deprotonation of materials is usually very low (less than $1 \%$ in weight). Thus the characterization of protonated materials by TGA method requires starting samples pure and dense, to avoid an overestimation of the mass loss caused by impurities or porosity ${ }^{[28]}$.

Despite the proton amount in the host structure is often very low, it is usually sufficient to obtain significant proton conduction through the materials $\left(>10^{-3} \mathrm{~S} / \mathrm{cm}\right)^{[25,27,30]}$. For instance, 
Orera et al. ${ }^{[19]}$ have studied the protonation of a powder of $\mathrm{La}_{8} \mathrm{Ba}_{2}\left(\mathrm{SiO}_{4}\right)_{6} \mathrm{O}_{2}$ lanthanum silicate at $400{ }^{\circ} \mathrm{C}$ for $48 \mathrm{~h}$ in a tube furnace under flowing nitrogen bubbled through water at room temperature $\left(\mathrm{pH}_{2} \mathrm{O} \approx 0.03 \mathrm{~atm}\right.$.). As this variation of mass was obtained below $600^{\circ} \mathrm{C}$, The low total weight loss of about $0.1 \%$ in weight could as well correspond to surface "protonic" species and not bulk.

The aim of this paper is the study of the protonation of Si-based oxyapatite $\mathrm{La}_{9.33+\mathrm{x}}\left(\mathrm{SiO}_{4}\right)_{6} \mathrm{O}_{2+3 \times / 2}$ dense ceramic pellets using a high pressure - high temperature autoclave in order to clarify the protonation mechanism in the oxides. This work corresponds to the first study about the eventual protonation of oxyapatite materials with oxygen substroichiometry $(x<0)$, oxygen-stoichiometry $(x=0)$ and oxygen over-stoichiometry $(x>0)$ at high water pressure (40-50 bars). Besides, an aging test was performed on the most promising sample of initial composition $\mathrm{La}_{9.60}\left(\mathrm{SiO}_{4}\right)_{6} \mathrm{O}_{2.4}$, in order to study the effect of the duration of the autoclave treatment on the stability and the protonation of the material. Ceramics were characterized by TGA an XRD. Raman spectroscopy was used in order to study the shortrange structure according to previous procedure $\left[{ }^{17,41},{ }^{42}\right]$. The proton insertion and its distribution/effect in the apatite structure have never been studied using Raman spectroscopy. We discuss here the Raman signature of the large lanthanum oxide channels before and after exposition to high water pressure.

\section{Experimental}

\subsection{Powder synthesis and sintering}

Powders of oxyapatite of general formula $\mathrm{La}_{9.33+\mathrm{x}}\left(\mathrm{SiO}_{4}\right)_{6} \mathrm{O}_{2+3 \mathrm{x} / 2}(\mathrm{x}=-0.2,0,0.27)$ were synthetized by solid state route from hexagonal $\mathrm{La}_{2} \mathrm{O}_{2} \mathrm{CO}_{3}$ and $\mathrm{SiO}_{2}$ reagents as explained in previous work $\left[{ }^{43,44}\right]$. After attrition milling in ethanol for 2 hours, the mixture was dried, heated at $1200^{\circ} \mathrm{C}$ for 4 hours and pressed by isostatic pressing into cylindrical bars at 2000 bars for 1 minute. Conventional sintering at $1550^{\circ} \mathrm{C}$ for 8 hours was used to densify the samples. Finally, the sintered samples were cut using a diamond wire saw in order to obtain dense pellets of $6 \mathrm{~mm}$ diameter and $1 \mathrm{~mm}$ thickness.

\subsection{High water pressure treatments}

Ceramic pellets of compositions $\mathrm{La}_{9.13}\left(\mathrm{SiO}_{4}\right)_{6} \mathrm{O}_{1.7}(\mathrm{La} 913), \mathrm{La}_{9.33}\left(\mathrm{SiO}_{4}\right)_{6} \mathrm{O}_{2}(\mathrm{La} 933)$, and $\mathrm{La}_{9.60}\left(\mathrm{SiO}_{4}\right)_{6} \mathrm{O}_{2.4}$ (La960) were wrapped in gold foil and put in an autoclave with 
decarbonated water for 84 hours at $550^{\circ} \mathrm{C}$ and 50 bars. After 12 hours of treatment, the pressure had decreased to 40 bars, that could indicate an eventual incorporation of water in the ceramic pellets. A second autoclave treatment was performed in the same initial conditions at $550^{\circ} \mathrm{C}$ and 50 bars for $0,24,72$ and 408 hours, on four pellets of composition La960. The notations La913_X, La933_X and La960_X (with X the duration of the high water pressure treatment in hours and "NP" indicating a non protonated sample) will be used in the following sections for the sake of clarity.

\subsection{Characterizations}

Microstructural observations of the samples were conducted on a JEOL 7400 FEGSEM scanning electron microscope. The pellets were polished and thermally etched prior to observation, and a 10nm thin gold layer was sputtered on their surface to prevent charging phenomenon.

Thermogravimetric analyses were performed on pieces of protonated samples in platinum crucible under helium flow of $20 \mathrm{ml} / \mathrm{min}$ from 50 to $1000^{\circ} \mathrm{C}$ with a heating rate of $5^{\circ} \mathrm{C} / \mathrm{min}$ (TG Setsys Evolution 2400, Setaram Instrumentation, Caluire, France). In order to minimize the experimental errors, the data were corrected by subtracting a reference curve obtained for each composition in the same experimental conditions with a non-protonated sample.

Phase purity of the pristine samples was controlled by X-ray powder diffraction on ground pellets at room temperature using $\mathrm{CuK}_{\alpha 1}$ radiation in the $2 \theta$ range $10-60^{\circ}$ with a step of $0.014^{\circ}$ and exposure time of $87 \mathrm{~s}$ per step (D8 advance diffractometer, Bruker, Germany).

Refinements of cell parameters were done in the space group $\mathrm{P}_{3} / \mathrm{m}$ following the Rietveld method $\left[{ }^{45}\right]$ using Jana2006 software $\left[{ }^{46}\right]$. XRPD intensities were collected in the $2 \theta$ range $15-100^{\circ}$, with a step of $0.014^{\circ}$ and exposure time of $261 \mathrm{~s}$ per step (D8 advance diffractometer, Bruker, Germany). The model used for these refinements comes from the work of Iwata et al. $\left[{ }^{12}\right]$. The continuous background was modelled with Legendre polynomial function and the peak profiles were represented by pseudo-Voigt functions.

Room temperature Raman spectroscopy was performed on the surface of samples before and after high water pressure treatment using a LabRam HR800 (Horiba Jobin-Yvon,) at the $514 \mathrm{~nm}$ wavelength in the single mode. The laser spot diameter at the focus point was about 2 micrometers (x100 Olympus long working distance objective) and the power was typically about $1 \mathrm{~mW}$ at the sample. 
Raman mapping has been done using a T64000 Horiba Jobin-Yvon spectrophotometer at the $514 \mathrm{~nm}$ wavelength, in the single mode. A 50LWD objective has been used in the backscattering mode. With both spectrophotometer, the spectra were averaged on the area of the bands between 130 and $600 \mathrm{~cm}^{-1}$ using LabSpec software. Each spectrum was decomposed into a sum of Lorentzian functions (corresponding to the refined bands $\left[{ }^{17,41,42}\right]$ ) using FOCUS software $\left[{ }^{47}\right]$.

\section{Results and discussion}

\subsection{Characterization of the non-protonated pristine ceramics}

X-ray powder diffraction patterns show in Figure 1 that oxyapatite samples synthetized in this study exhibit a high purity, with only small amount of secondary phase $\mathrm{La}_{2} \mathrm{Si}_{2} \mathrm{O}_{7}$ (JCPDS 81-0461) in La913 and La933. All sintered samples had a relative density higher than $98.5 \%$.

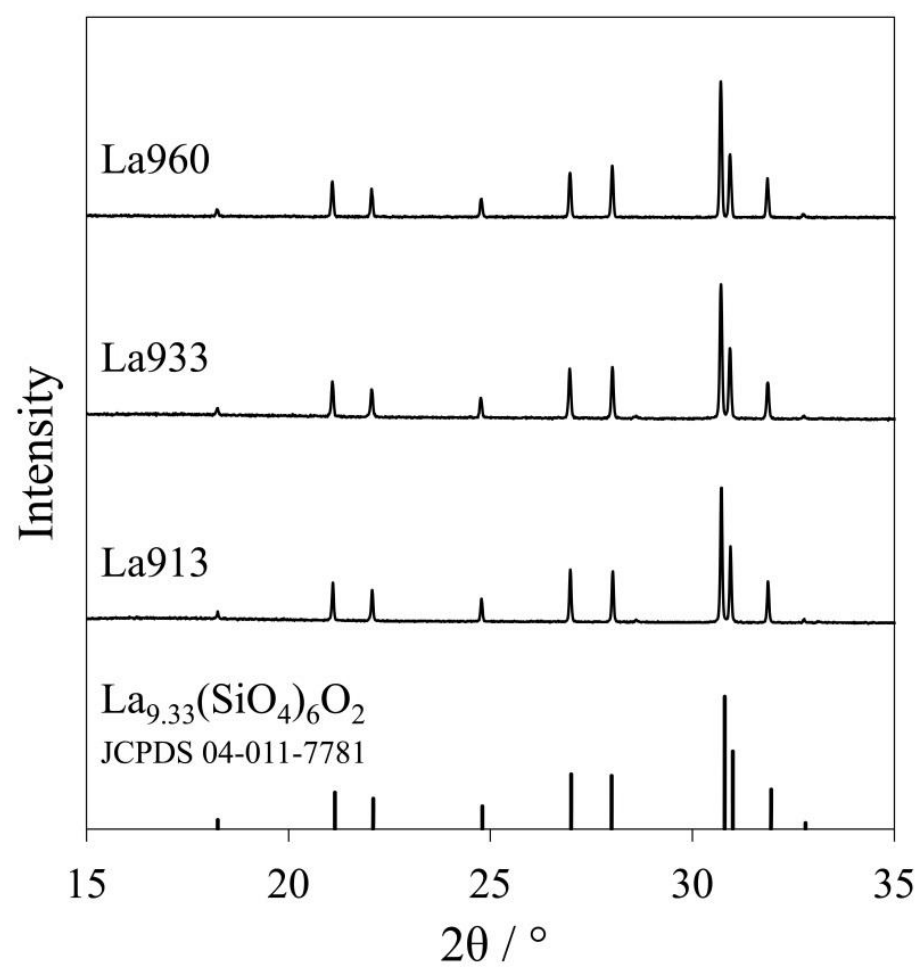

Figure 1 : X-ray diffraction patterns for powdered oxyapatite ceramics of chemical composition $\mathrm{La}_{9.13}\left(\mathrm{SiO}_{4}\right)_{6} \mathrm{O}_{1.7}(\mathrm{La} 913), \mathrm{La}_{9.33}\left(\mathrm{SiO}_{4}\right)_{6} \mathrm{O}_{2}(\mathrm{La} 933)$ and $\mathrm{La}_{9.60}\left(\mathrm{SiO}_{4}\right)_{6} \mathrm{O}_{2.405}$ (La960) compared with the standard $\mathrm{La}_{9.33}\left(\mathrm{SiO}_{4}\right)_{6} \mathrm{O}_{2}$. 
The average grain size shown in SEM micrographs of the pristine samples $\left[{ }^{43}\right]$ is about a few micrometers, with a grain size slightly higher for oxygen deficient sample as discussed in a previous work $\left[{ }^{17,43,44,48}\right]$. This quite large size should be favorable for the incorporation of protonated species, as discussed by Pasteris et al. in the temperature study of the $\mathrm{Ca}_{10}\left(\mathrm{PO}_{4}\right)_{6} \mathrm{OH}$ system $\left[{ }^{49}\right]$. They conclude that the smaller the crystallites, the higher the atomic disorder is, thus making the incorporation of $\mathrm{OH}^{-}$ions less energetically favorable. This shows that it is very important to get large grains for the optimization of the protonation step, and also to limit grain boundary effects.

Thermogravimetry method is very sensitive to detect traces of volatile species such as water (mass losses before $150^{\circ} \mathrm{C}$ ), hydroxides (mass losses before $400^{\circ} \mathrm{C}$.) and carbonates (mass losses before $1000^{\circ} \mathrm{C}$ ). Before protonation, the weight loss of samples was measured twice during a heating up to $1200^{\circ} \mathrm{C}$. The mass loss of the unprotonated pellet was about $0.1 \%$ for the first heating cycle and $0.05 \%$ for the second one. There is no water or carbonate adsorbed at the surface of the sample, as no mass loss occured at low temperature. Also, there was no oxygen loss due to eventual reduction of material under helium atmosphere at high temperature.

A Raman spectroscopy study of the pristine samples was used to determine the bands which are the signature of the high pressure treatment. A typical Raman spectrum of oxyapatite is presented in Figure 2(a), decomposed into a sum of Lorentzian functions using FOCUS software $\left[{ }^{47}\right]$ according to previous procedure $\left[{ }^{17}\right]$. The corresponding calculated bands $\left[{ }^{17,41,42}\right]$ are given in Table 1 . In this work we focus our attention on the wavenumber range below $600 \mathrm{~cm}^{-1}$ which is mostly affected by high pressure treatment.

Modes $\mathrm{Au}, \mathrm{Ag}, \mathrm{Eg}$ and $\mathrm{Eu}$ given in Table 1 are assigned to the vibrations of oxygen O5 in the large tunnels of oxyapatite structure. These modes were described by Smirnov et al. $\left[{ }^{42}\right]$ in the case of Sr-doped oxyapatite $\mathrm{La}_{8} \mathrm{Sr}_{2}\left(\mathrm{SiO}_{4}\right)_{6} \mathrm{O}_{2}$ thanks to ab initio calculation. The data presented in Table 1 result from a projection of Smirnov's results in the case of compounds $\mathrm{La}_{9.33+\mathrm{x}}\left(\mathrm{SiO}_{4}\right)_{6} \mathrm{O}_{2+3 \times / 2}$.

According to the principle of mutual exclusion in the case of centro-symmetrical structure, modes $\mathrm{Ag}$ and $\mathrm{Eg}$ are Raman active while modes $\mathrm{Au}$ and $\mathrm{Eu}$ are IR active. However, bands attributed to modes $\mathrm{Au}$ and Eu can be observed in oxyapatite Raman spectra $\left[{ }^{17,41,42,44}\right]$, meaning that real symmetry of the large tunnels of oxyapatite is slightly different from the perfect symmetry. Béchade et al. $\left[{ }^{17}\right]$ showed these modes are affected by the change 
of oxygen stoichiometry (insertion of interstitial oxygen in the large tunnel of the structure involving a proposed push-pull mechanism $\left.\left[{ }^{14,17}\right]\right)$.

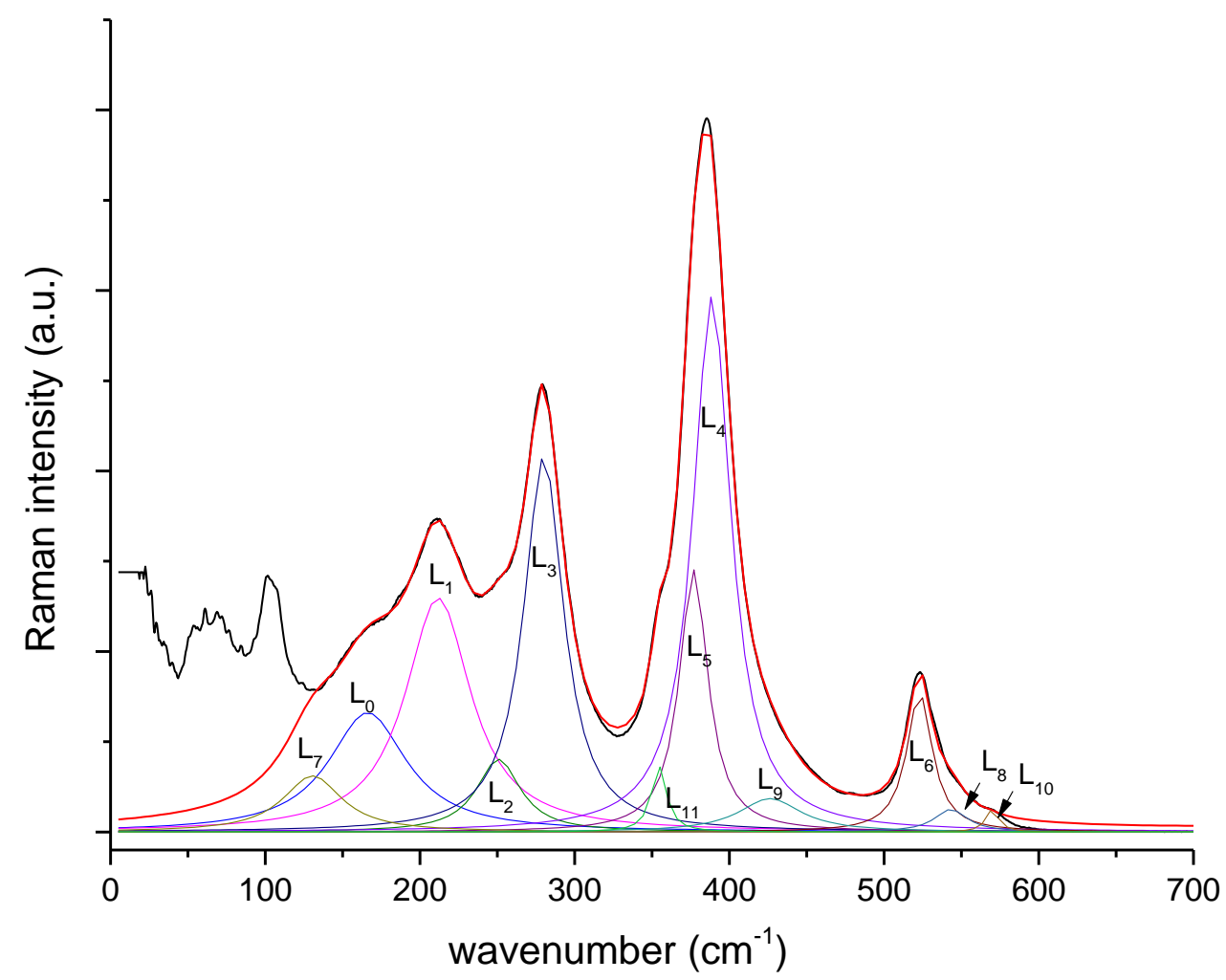

Figure 2: a) Decomposition of the spectrum of oxyapatite (example of La960_NP) at low wavenumbers (from 100 to $600 \mathrm{~cm}^{-1}$ ).

Table 1: Attribution of the Raman vibration bands refined for the compounds $\mathrm{La}_{9.33+\mathrm{x}}\left(\mathrm{SiO}_{4}\right)_{6} \mathrm{O}_{2+3 \times / 2}\left[{ }^{17,41,42}\right]$.

\begin{tabular}{ccc}
\hline Lorentzian & $\begin{array}{c}\text { Raman wavenumber } \\
\left(\mathrm{cm}^{-1}\right)\end{array}$ & Attribution \\
\hline L7 & 135 & Lattice modes \\
\hline L0 & 180 & La2- $\mathrm{O}_{(\mathrm{SiO} 4)}$ vibrations \\
L1 & 213 & \\
L3 & 276 & Symmetric bending mode of SiO4 $\left(v_{2}\right)$ and $\mathrm{La}_{2}-\mathrm{O}_{(\mathrm{SiO} 4)}$ vibrations \\
L4 & 393 & Asymmetric bending mode of SiO4 $\left(v_{4}\right)$ \\
L5 & 372 & Eg mode: \\
L6 & 523 & Vibration of O5 oxygen in the xy plane \\
L8 & 543 & \\
\hline L9 & 430 &
\end{tabular}




\begin{tabular}{ccc}
\hline L10 & 570 & $\begin{array}{c}\text { Eu mode: } \\
\text { Vibration of O5 oxygen in the xy plane }\end{array}$ \\
\hline L11 & 355 & $\begin{array}{c}\text { Ag mode: } \\
\text { Symmetric vibration of O5 oxygen in the direction parallel to z }\end{array}$ \\
\hline L2 & 250 & Au mode: \\
\end{tabular}

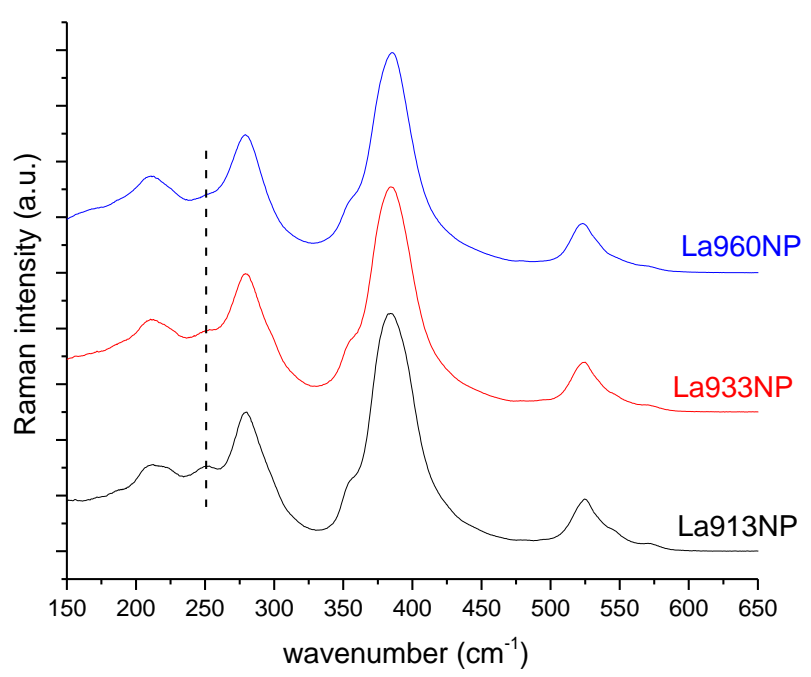

Figure 5: Raman spectra obtained on non protonated samples La913, La933 and La960.

Figure 3 evidences the stoichiometry effect by showing the comparison of Raman spectra measured on samples La913_NP, La933_NP and La960_NP before autoclave treatment. The band which is the most affected by the change of stoichiometry is the Lorentzian noted L2 related to the so-called Au mode. A significant increase of its full width at half maximum (FWHM) can be observed as shown in table 2. This trend can be explain by the creation of an important disorder inside the large channels due to the incorporation of anions in the oxyapatite structure, as reported by other works [9,11,13,14,17,18 $]$.

Table 2: Refined widths at half-height $\mathrm{w}_{\alpha}$ in $\mathrm{cm}^{-1}$ of Lorentzians $\mathrm{L} \alpha$ (with $\alpha=[0-2]$ ) in the case of unprotonated samples La913_NP, La933_NP, La960_NP.

La913_NP La933_NP $\quad$ La960_NP




$\begin{array}{llll}\text { FWHM (L2) }\left(\mathrm{cm}^{-1}\right) & 29.23 & 31.37 & 34.29\end{array}$

\subsection{Composition effect on the protonation of the ceramics}

Thermogravimetric analyses performed on oxyapatite samples of different compositions after autoclave treatment $\left(84 \mathrm{~h} / 550^{\circ} \mathrm{C} / 40 \mathrm{bars}\right)$ are showed in Figure 4 . One can notice that after being exposed to high water pressure, all the samples exhibit a mass loss between 100 and $1000^{\circ} \mathrm{C}$. Thus the autoclave treatment seems to have affected the material in all cases. Furthermore, two different mass losses are noticeable for each sample: from $100^{\circ} \mathrm{C}$ to $600^{\circ} \mathrm{C}$ and from $600^{\circ} \mathrm{C}$ to $1000^{\circ} \mathrm{C}$. Colomban et al. $\left[^{25,26,27}\right]$ showed that, in the case of perovskite-type materials after autoclave treatment, a mass loss observed while heating a protonated sample below $600^{\circ} \mathrm{C}$ corresponded to surface "protonic" species while a mass loss happening above $600^{\circ} \mathrm{C}$ corresponded to volume "protonic" species. In the case of a protonconducting electrolyte for SOFC application, the involved species must be located in the volume/bulk of the material.

Mass losses observed while heating the material above $600{ }^{\circ} \mathrm{C}$ are about $0.09 \%, 0.11 \%$ and $0.20 \%$ for samples La913_84, La933_84 and La960_84 (Table 3). Thus, the higher the oxygen stoichiometry, the larger the total mass loss is. As a comparison, Orera and Slater $\left[{ }^{19}\right]$ observed a mass loss of about $0.4 \%$ above $600^{\circ} \mathrm{C}$ on a sample of composition $\mathrm{La}_{6} \mathrm{~Tb}_{4}\left(\mathrm{GeO}_{4}\right)_{6} \mathrm{O}_{3}$ after an autoclave treatment of 48 hours at $200^{\circ} \mathrm{C}$ and 15 bars. One may note that Orera and Slater $\left[{ }^{19}\right]$ used samples are in the form of powder, contrary to our work which involves dense samples $\left(d_{\text {rel }}>98.5 \%\right)$. This is important in so far as the density of the sample is a key parameter for water incorporation in the material. Indeed, Colomban et al. $\left[{ }^{27}\right]$ show that the relative density must be higher than $94 \%$ for the samples in order to promote insertion of water in the volume of the material (instead of the surface). Furthermore, $\mathrm{GeO}_{2}$ solubility in water is several orders of magnitude higher than that of $\mathrm{SiO}_{2}$ and partial hydrolysis may have happened in Ge-based oxyapatite $\mathrm{La}_{6} \mathrm{~Tb}_{4}\left(\mathrm{GeO}_{4}\right)_{6} \mathrm{O}_{3}$, leading to an increase of the total mass loss.

The studies about the protonation of oxides under high water pressure at moderate temperature $\left(600^{\circ} \mathrm{C}\right)$ are very scarce in the literature, thus it is not possible to compare the data collected in this work with other data collected in the literature. 


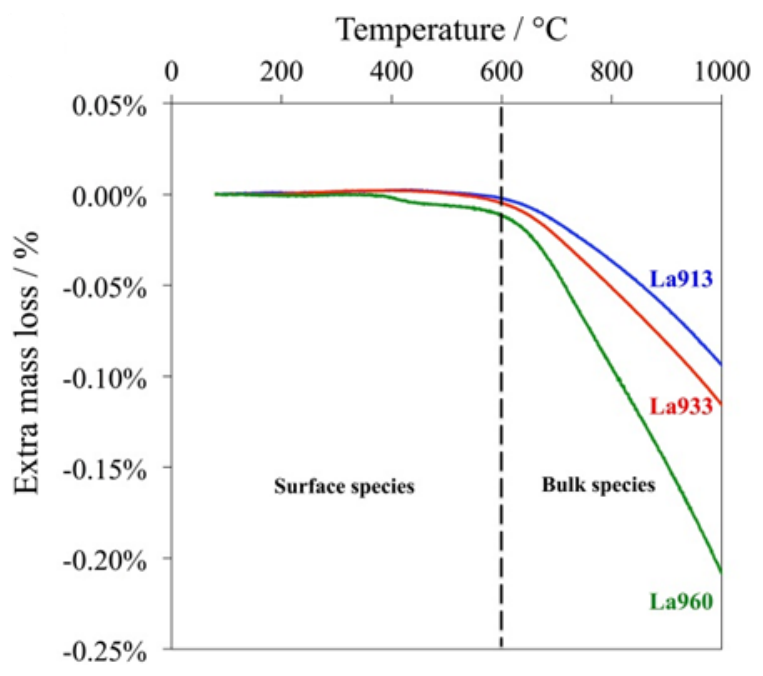

Figure 4: TGA performed on oxyapatite samples La913, La933 and La960 after autoclave treatment at $550^{\circ} \mathrm{C} / 40 \mathrm{bars} / 84 \mathrm{~h}$. Data are corrected by subtraction of the signal monitored for unprotonated samples La913, La933 and La960 respectively.

Table 3: Mass losses of protonated samples observed by thermogravimetry. Comparison with

$$
\mathrm{La}_{6} \mathrm{~Tb}_{4}\left(\mathrm{GeO}_{4}\right)_{6} \mathrm{O}_{3}\left[{ }^{19}\right]
$$

\begin{tabular}{cccc}
\hline Sample & $\begin{array}{c}\text { Autoclave } \\
\text { treatment }\end{array}$ & $\begin{array}{c}\text { Total mass } \\
\text { loss } 100^{\circ} \mathrm{C}\end{array}$ & $\begin{array}{c}\text { Mass loss } \\
\text { to } 1000^{\circ} \mathrm{C}\end{array}$ \\
& & $600^{\circ} \mathrm{C}$ \\
& & $(\%)$ & $(\%)$ \\
\hline La913_84 & $84 \mathrm{~h} / 550^{\circ} \mathrm{C} / 40$ bars & 0.09 & 0.09 \\
La933_84 & $84 \mathrm{~h} / 550^{\circ} \mathrm{C} / 40$ bars & 0.12 & 0.11 \\
La960_84 & $84 \mathrm{~h} / 550^{\circ} \mathrm{C} / 40$ bars & 0.21 & 0.20 \\
$\mathrm{La}_{6} \mathrm{~Tb}_{4}\left(\mathrm{GeO}_{4}\right)_{6} \mathrm{O}_{3}$ & $48 \mathrm{~h} / 200^{\circ} \mathrm{C} / 15 \mathrm{bars}$ & 1.76 & 0.40 \\
\hline
\end{tabular}

In these samples, the composition La913 (with oxygen vacancies, $\mathrm{V}_{\mathrm{O}}^{\bullet \bullet}$ ) is the one that shows the lowest mass loss. Thus, protonation mechanism by oxygen vacancies as proposed in equations (1a), (1b) and (1c) does not seem to be the predominant protonation mechanism in the case of oxyapatite.

On the contrary, composition La960 exhibits the larger mass loss, so high initial oxygen stoichiometry seems to promote protonation of oxyapatite. This is a good agreement with the study of Orera and Slater $\left[{ }^{19,20}\right]$, who explain the incorporation of protons in Si and Ge-based oxyapatites, as previously presented in equations (2), (3) and (4). 
Contrary to equations (1a, b and c), these mechanisms don't involve oxygen vacancies but oxygen atoms of the network $\boldsymbol{O}_{\boldsymbol{o}}$ and interstitial oxygen atoms $\boldsymbol{O}_{\boldsymbol{i}}^{\prime \prime}$. They are leading to the formation of hydroxide ions on the sites of oxygen of the network $\left(\boldsymbol{O H}_{\boldsymbol{O}}\right)$, interstitial hydroxide ions $\left(\boldsymbol{O} \boldsymbol{H}_{\boldsymbol{i}}^{\prime}\right)$ and additional interstitial oxide ions $\boldsymbol{O}_{\boldsymbol{i}}^{\prime \prime}$.

As the apatite samples were exposed, to very extreme conditions of temperature and pressure in this work $\left(550^{\circ} \mathrm{C}, 40-50\right.$ bars), one can also consider reaction (5). This equation describes the dissociation of water and its incorporation in the structure of the material under the influence of high pressure and temperature. This results in the formation of two interstitial protons and an interstitial oxygen atom.

$$
\mathrm{H}_{2} \mathrm{O}_{(\mathrm{g})} \leftrightarrow 2 \mathrm{H}_{i}^{\bullet}+\mathrm{O}_{i}^{\prime \prime}
$$

It is to note that in all cases (equations (2) to (5)), protonation of oxyapatite may induce the incorporation of oxygen on interstitial site, in the form of $\boldsymbol{O} \boldsymbol{H}_{\boldsymbol{i}}^{\prime}$ or $\boldsymbol{O}_{\boldsymbol{i}}^{\prime \prime}$.

On a structural point of view, in the case of protonated samples La913_84, La933_84 and La960_84, it was not possible to refine the width at half-height of the Lorentzians, because the band at $250 \mathrm{~cm}^{-1}$ (attributed to the Au mode) forms a very small shoulder on the massif at $280 \mathrm{~cm}^{-1}$ and because this massif is shifted to the lower wavenumbers. However, as seen in Figure 5, the bands Ag and Eg are modified as compared to the ones measured in nonprotonated samples. For example, the band at $440 \mathrm{~cm}^{-1}$, which is attributed to Eg mode, is more visible on spectra of protonated samples (La913_84, La933_84 and La960_84) than on the spectra of the unprotonated samples (La913_NP, La933_NP and La933_NP in Figure 3). This is in agreement with previous study of Orera et al. $\left[{ }^{19,20}\right]$ and this assumes that La-O bonds close to the channel are modified. 


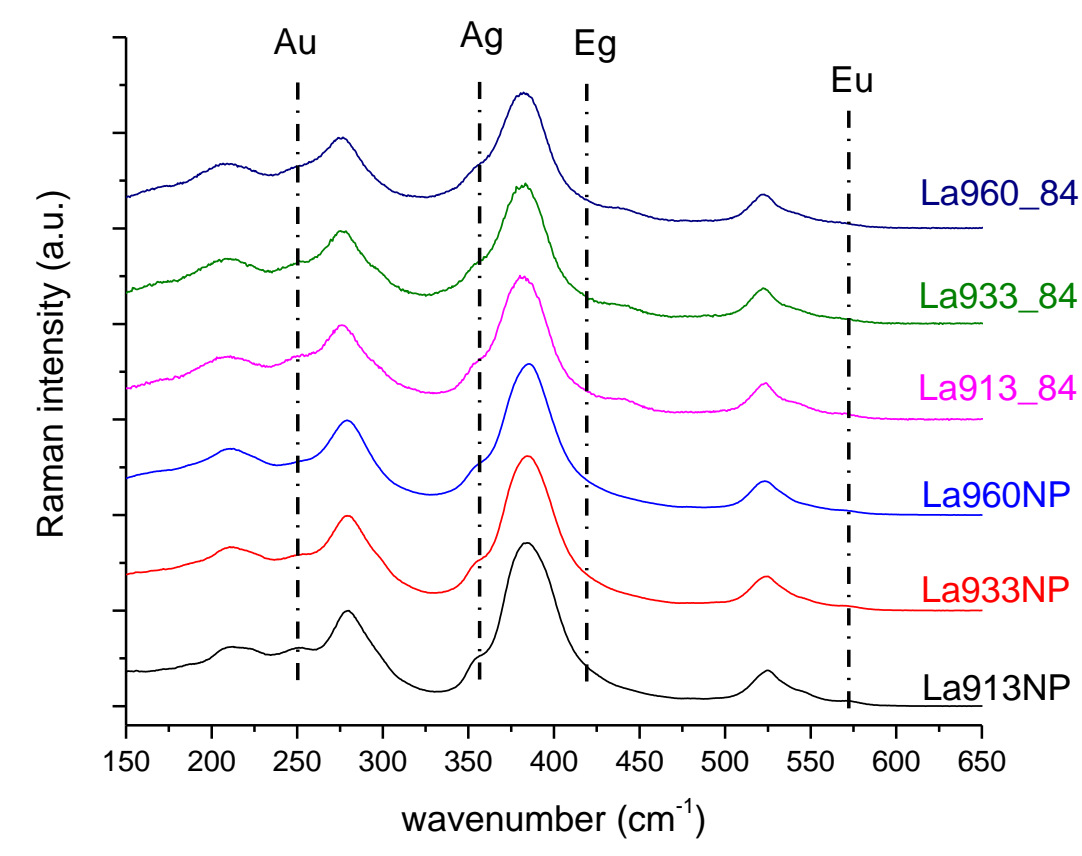

Figure 5: Raman spectra obtained with an incident wavelenght of $514.5 \mathrm{~nm}$ samples La913, $\mathrm{La} 933$ and La960 protonated $84 \mathrm{~h}$ at $500^{\circ} \mathrm{C}$ and 40 bars.

Moreover we recorded wide spectral range (100-5000 $\left.\mathrm{cm}^{-1}\right)$ Raman spectra on samples La913_84, La933_84 and La960_84 and on a pristine sample (Figure 6). On one hand, a large luminescence band was observed between 1000 and $4500 \mathrm{~cm}^{-1}$ (centred approximately at $2500 \mathrm{~cm}^{-1}$ ) in the case of protonated samples La913_84 and La933_84 but not in the case of protonated sample La960_84.

This band seems to be similar to the one observed in the case of perovskite materials by Colomban et al. ${ }^{[24,27,28,29]}$, in this point of view we can suppose that this phenomenon may be due to the creation of electronic defects in relation to water exposure (proton/oxygen diffusion). In the case of La960_84 sample, the lack of intrinsic oxygen vacancies should be noted and may induced different phenomena ${ }^{[44]}$. 


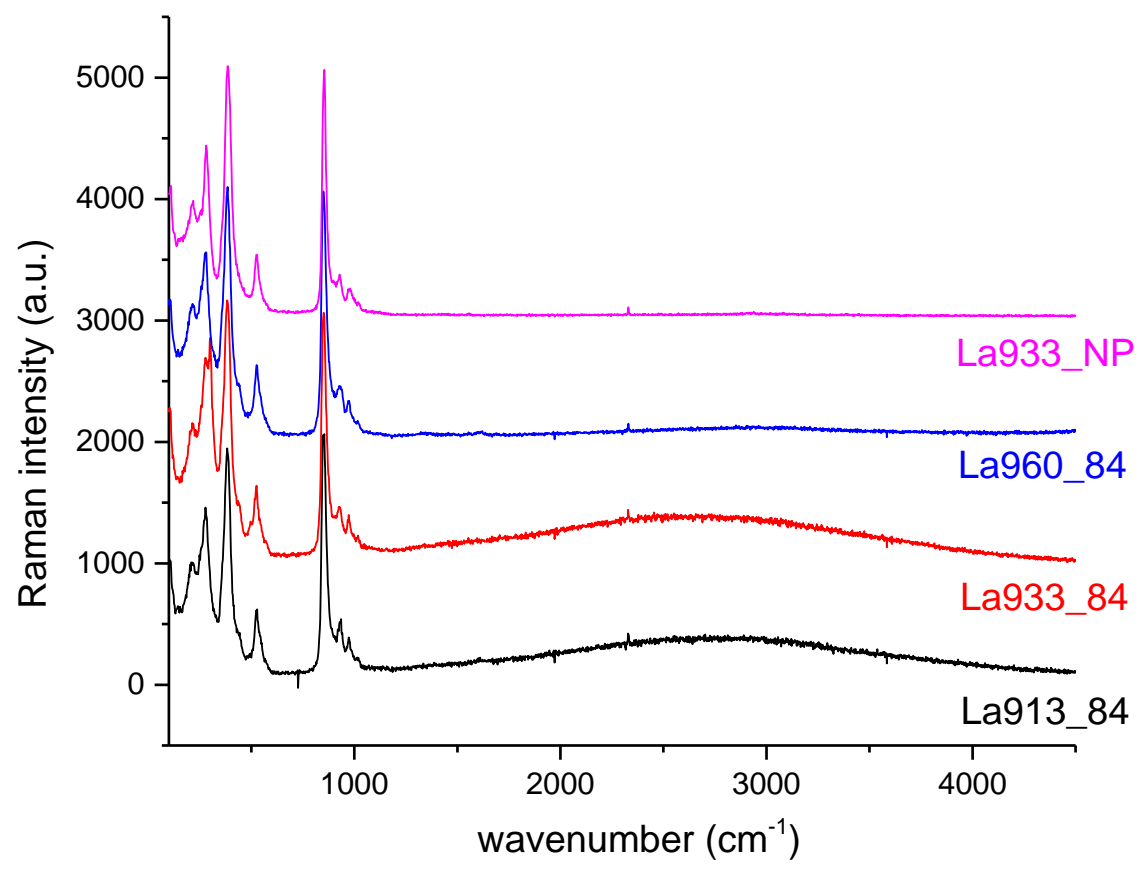

Figure 6. Raman spectra monitored in spectral range $100-4500 \mathrm{~cm}^{-1}\left(\lambda_{\text {inc }}=514.5 \mathrm{~nm}\right)$ on protonated oxyapatite samples La913_84, La933_84, La960_84 and on unprotonated sample (La933_NP) for comparison.

As an illustration, Raman mapping performed on the fresh surface of an unprotonated sample La913_NP and a protonated sample La913_84 is shown on Figure 7. Studied areas are represented by orange rectangles on the optical microscopy images. Raman picture is reconstructed on the integrated intensity of the area of the wavenumber range between 1100 and $4000 \mathrm{~cm}^{-1}$ in both cases. The intensity has been normalizing between 0 and 100 for the two maps to be able to compare both images. Protonated sample map clearly evidence that luminescence phenomenon is not homogeneous on the surface of the sample because of the strong contrast of colour related to the huge difference of the integrated intensity of the band under study whereas the non-protonated sample map evidence no luminescence phenomenon at the entire surface (only one colour evidence a very low intensity of the integrated intensity of the band under study). Areas of the mapping where the intensity of the band is the highest (in red/yellow) seem to correspond to white areas on the optical microscopy images. Such an inhomogeneity of the luminescence phenomenon could be due to an inhomogeneity of the microstructure or structure of the material. As shown on Figure 7, all grains are not affected and it could be possible that grain orientation is an important parameter. However, the areas where the intensity is the highest (in red/yellow) have dimensions higher than $100 \mu \mathrm{m}^{2}$, which 
is much higher that the grain size. So, further investigation is necessary to understand this phenomenon.

a)
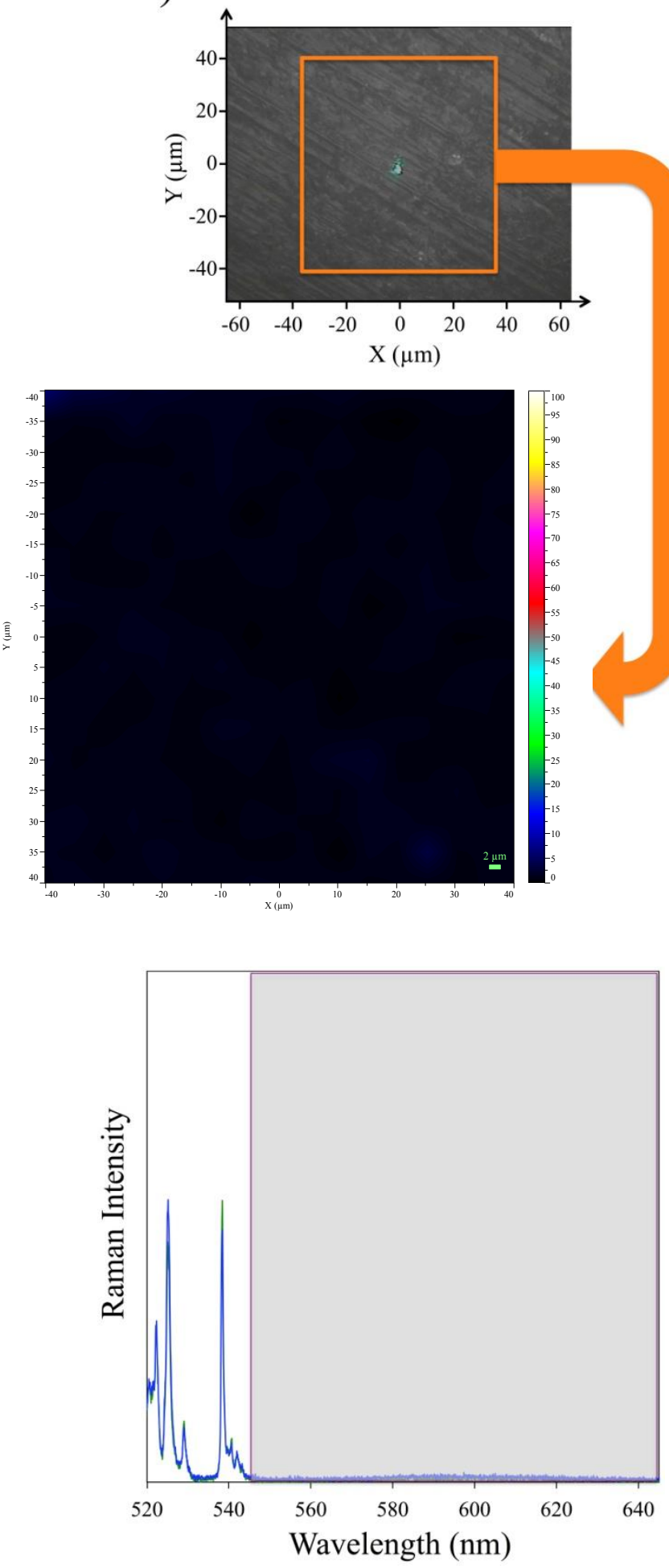

b)
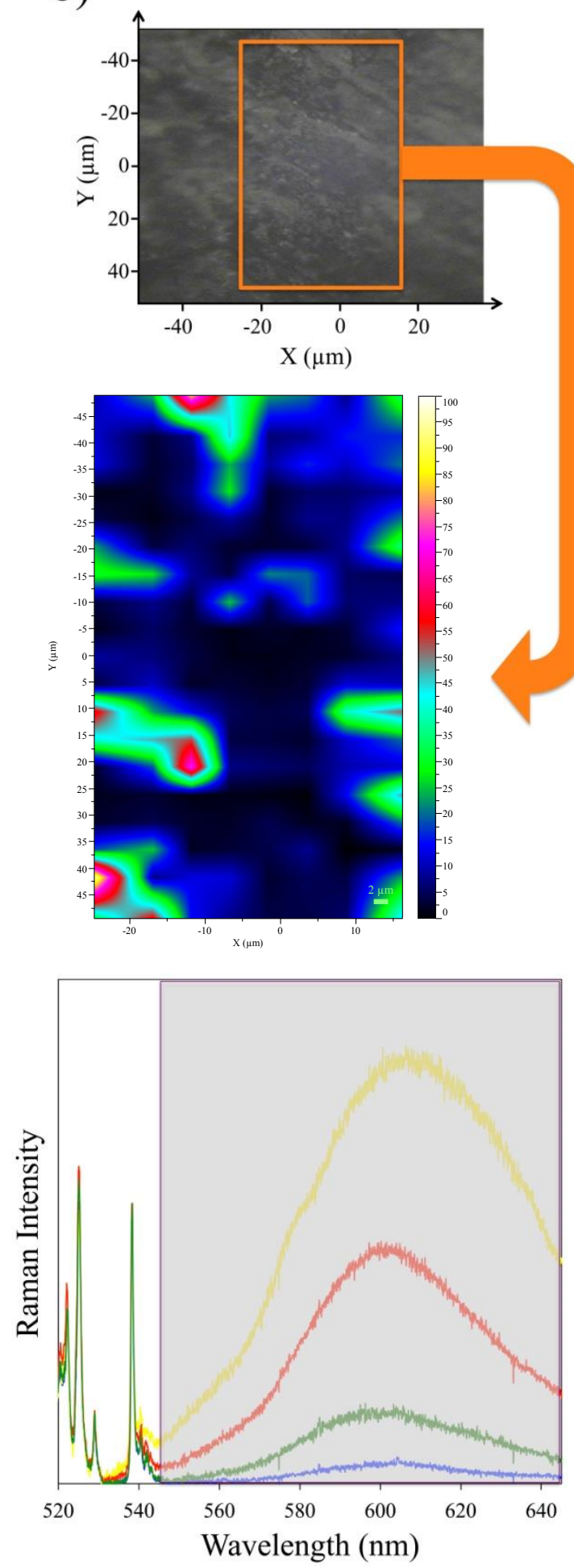

Figure 7: Mapping (a) of La913_NP (b) La913_84, optical view of the mapped area and corresponding representative spectra 


\subsection{Protonation of La960}

Samples with the composition La960 being the most favorable in the incorporation of protonic species, a further study was conducted to see the influence of longer time treatments in autoclave. Pellets were placed in the autoclave at $550^{\circ} \mathrm{C}$ and 50 bars for durations of $24 \mathrm{~h}$, 72 and 408h. The thermogravimetric curves of the protonated samples are given in Figure 8. Mass losses observed while heating the material above $600^{\circ} \mathrm{C}$, given in Table 4 , are about $0.14 \%, 0.19 \%, 0.66 \%$ for samples La960_24, La960_72, La960_408 respectively. In this series of samples, there seems to be more surface protonic species than in the previous section, characterized by a larger mass loss in the range $100^{\circ} \mathrm{C}-600^{\circ} \mathrm{C}$. Concerning volume species, the mass loss increases with the protonation time, showing some kinetic effect to the phenomenon.

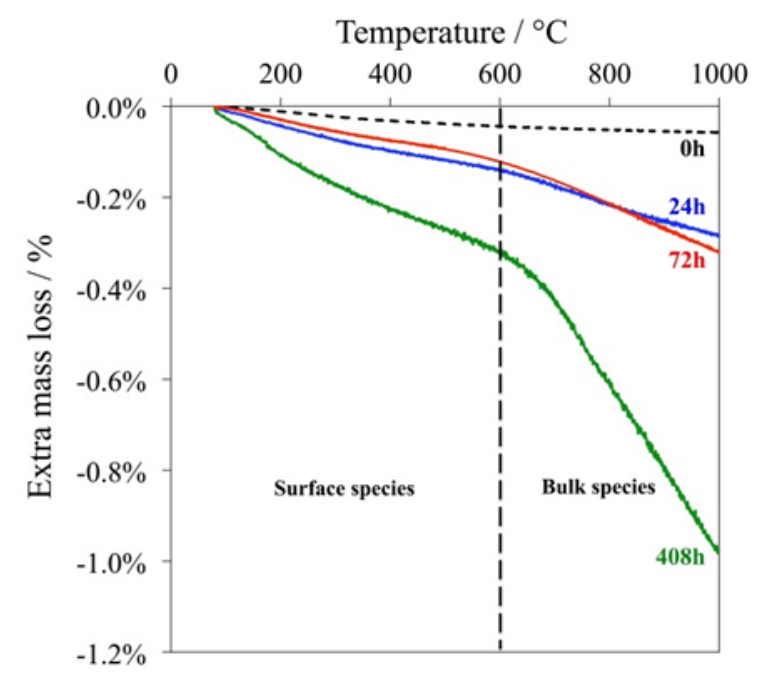

Figure 8: TGA performed on oxyapatite samples La960 after autoclave treatment at $550^{\circ} \mathrm{C} / 50$ bars for $24 \mathrm{~h}, 72 \mathrm{~h}$ and $408 \mathrm{~h}$.Data are corrected by subtraction of the signal monitored for unprotonated samples.

Table 4: Mass losses of La960 samples protonated for different durations observed by thermogravimetry.

\begin{tabular}{cccc}
\hline & & Total mass & Mass loss \\
Sample & Autoclave & loss $100^{\circ} \mathrm{C}$ & above \\
& treatment & to $1000^{\circ} \mathrm{C}$ & $600^{\circ} \mathrm{C}$ \\
& & $(\%)$ & $(\%)$ \\
\hline La960_24 & $24 \mathrm{~h} / 550^{\circ} \mathrm{C} / 50$ bars & 0.28 & 0.14
\end{tabular}




$\begin{array}{cccc}\text { La960_72 } & 72 \mathrm{~h} / 550^{\circ} \mathrm{C} / 50 \mathrm{bars} & 0.32 & 0.19 \\ \text { La960_408 } & 408 \mathrm{~h} / 550^{\circ} \mathrm{C} / 50 \mathrm{bars} & 0.98 & 0.66\end{array}$

The microstructure of the polished and thermally etched pellets before and after the protonation process is shown in Figure 9. The unprotonated sample, Figure 9a, shows a grain size distribution of $0.5 \mu \mathrm{m}$ to $2 \mu \mathrm{m}$ with no porosity. After $24 \mathrm{~h}$ in the autoclave, the microstructure of the pellet remains largely unaffected (Figure 9b). However some striations can be observed on some grains of the sample. They don't seem to be preferentially present on small or big grains but randomly distributed. The sample protonated during 72 hours (Figure 9c) is characterized by a visible surface corrosion and striations on the whole sample. After $408 \mathrm{~h}$ of autoclave treatment, the microstructure of the sample is widely damaged (Figure 9d). Some gains are so extensively corroded that their boundaries are not visible. Once again, the effect does not seem to be related to the grain size.

However, it is interesting to note that the oxyapatite samples are very stable under those harsh conditions. The pressure values in this work are 2-5 times higher than that required in an industrial use $\left[{ }^{50}\right]$. Although the sample treated during 408 hours broke during the protonation, probably due to a too large modification of the cell parameters, the pellets are still in good condition after protonation. It is not the case with perovskite-based materials, for example, $\mathrm{BaCe}_{0,5} \mathrm{Zr}_{0,3} \mathrm{Y}_{0,16} \mathrm{Zn}_{0,04} \mathrm{O}_{3-\delta}$, which was damaged after 30 hours of autoclave treatment in much smoother conditions, namely $500^{\circ} \mathrm{C}$ and 10 bars $\left[{ }^{28}\right]$. 

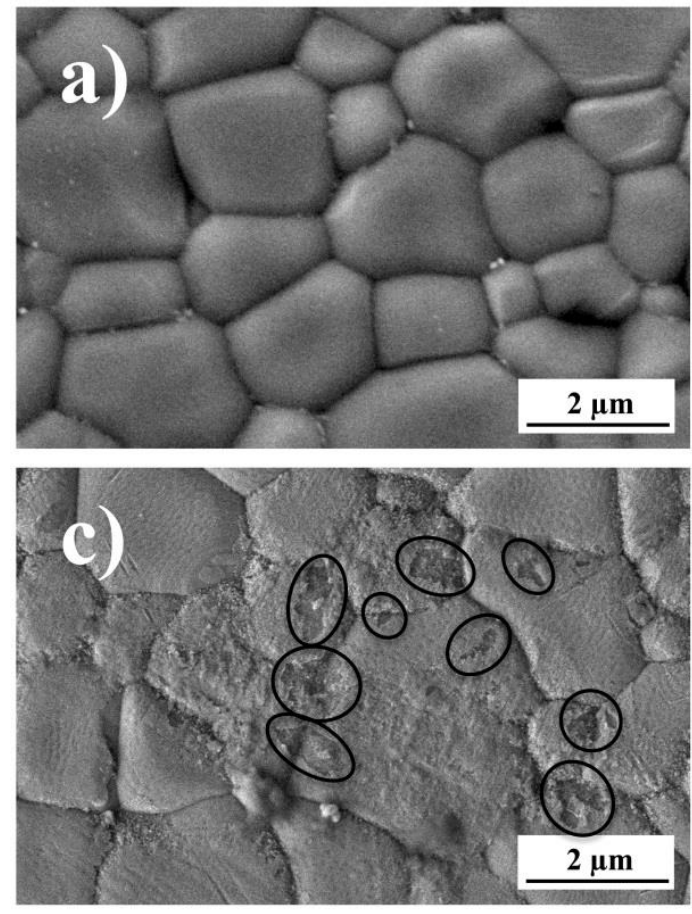
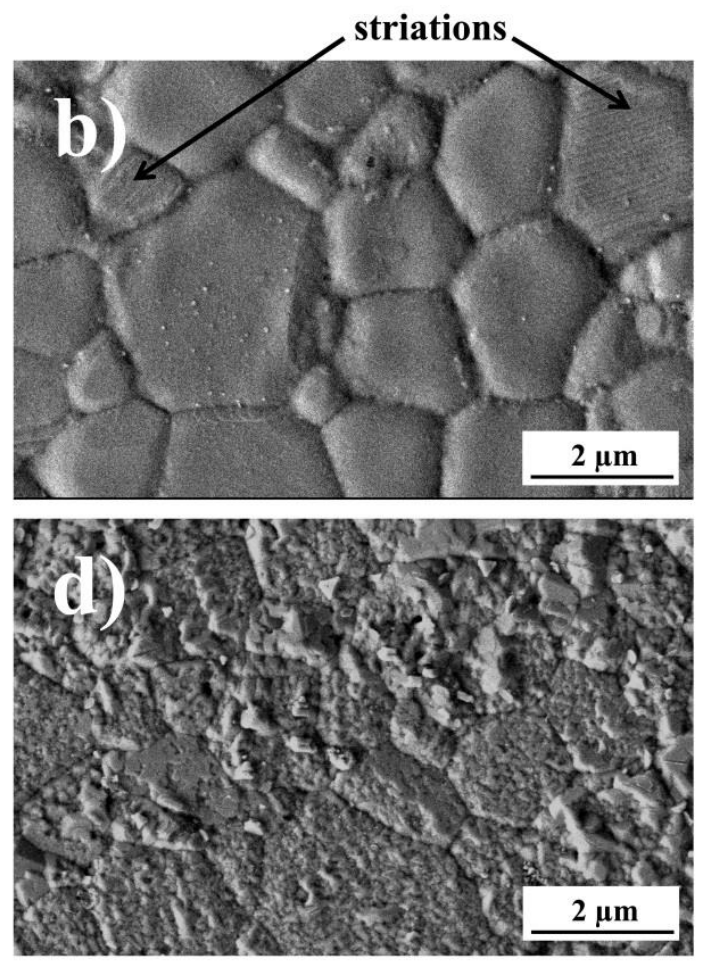

Figure 9: SEM micrographs of the La960 sample after a) 0h, b) 24h, c) $72 \mathrm{~h}$ and d) $408 \mathrm{~h}$ of protonation at $550^{\circ} \mathrm{C}$ and 50 bars. Circles indicate the appearance of a second zone with different contrast.

Rietveld refinement of lattice parameters of sample La960 (Figure 10a) were performed before and after autoclave treatment at $550^{\circ} \mathrm{C}, 50$ bars, $72 \mathrm{~h}$. This sample was chosen because it had the larger mass loss with no damage of the microstructure. Changes were observed between the diagrams of protonated and unprotonated samples (Figure 10b). Indeed, after autoclave treatment, the full width at half maximum is larger and the peaks' profiles seem asymmetric. After a closer examination, however, the profiles of the peaks corresponding to the plans $(0,0, l)$ are not affected. Thus the autoclave treatment seems to induce structural modifications but the $c$ direction is not involved (anisotropic structural modification). Furthermore, in the case of the autoclave-treated sample, what seemed to be asymmetry could be in fact modelled using two apatite phases of same symmetry and different lattice parameters (phases named \#1 and \#2 in Figure 10b). 

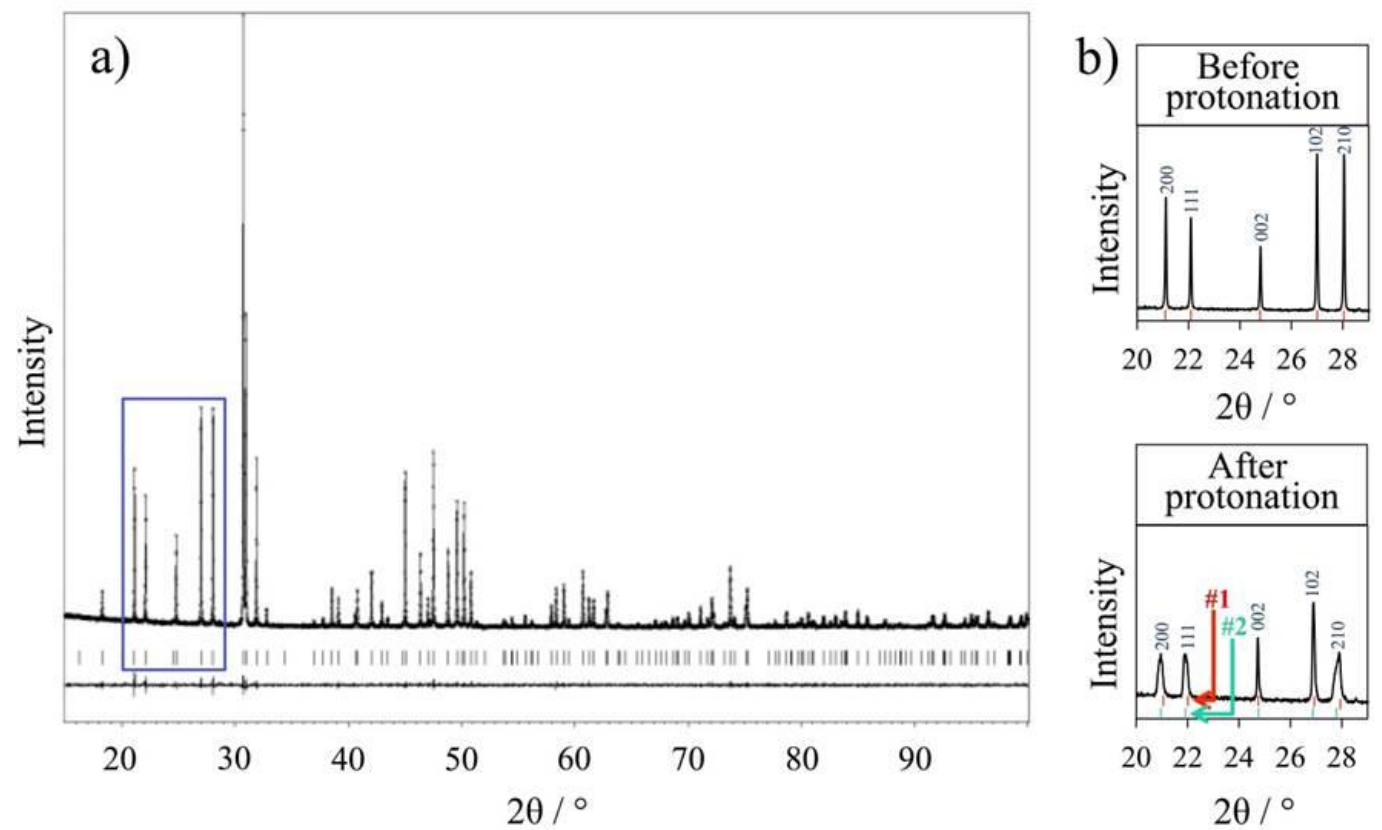

Figure 10: a) Comparison of the observed diffraction pattern $($ symbol +) with the corresponding calculated pattern (upper solid line) for La960_72. The vertical bars indicate the position of possible Bragg reflections. The difference curve is shown in the lower part of the diagram. The blue square shows the area more specifically analysed in (b). b) Comparison in the $2 \theta$-range $\left[20^{\circ}-29^{\circ}\right.$ ] of the XRDP of La960_NP and after protonation at $550^{\circ} \mathrm{C} / 50$ bars/72h (lower part). \#1 and \#2 represent two apatite phases with different lattice parameters.

As shown in Table 5, lattice parameters of the non-protonated sample and of phase \#1 of the autoclave-treated sample are similar $(a=b \approx 9.7 \AA$ and $c \approx 7.2 \AA$ ). On the contrary, lattice parameters $a$ and $b$ of phase \#2 are larger $(a=b \approx 9.8 \AA)$ while $c$ remains constant, which is in good agreement with an anisotropic structural modification. The volume of the unit cell in phase \#2 of the autoclave-treated sample $\left(V \approx 597.69 \AA^{3}\right)$ is much larger than the one of the non-protonated sample $\left(V \approx 587.69 \AA^{3}\right)$. The values reported in literature $(V \approx$ $587.77 \AA^{3}$ and $587.08 \AA^{3}$ for $\mathrm{La}_{9.33}\left(\mathrm{SiO}_{4}\right)_{6} \mathrm{O}_{2}$ and $\mathrm{La}_{10}\left(\mathrm{SiO}_{4}\right)_{6} \mathrm{O}_{3}$ respectively $\left[{ }^{9}\right], V \approx 588.93$ $\AA^{3}$ and $588.94 \AA^{3}$ for $\mathrm{La}_{9.16}\left(\mathrm{SiO}_{4}\right)_{6} \mathrm{O}_{1.75}$ and $\mathrm{La} 9.33\left(\mathrm{SiO}_{4}\right)_{6} \mathrm{O}_{2}$ respectively $\left.\left[{ }^{51}\right]\right)$ show that the volume of the unit cell is not as much affected by the oxygen content and that the variation of the results (for the composition $\left.\mathrm{La}_{9.33}\left(\mathrm{SiO}_{4}\right)_{6} \mathrm{O}_{2}\right)$ between the two studies is about $1 \AA$. As a comparison, the variation of the unit cell volume, between the non-protonated sample and the phase \#2 of the autoclave-treated sample, is about $10 \AA$.

Such a large increase of the unit cell volume, correlated with the increase of the a and b lattice parameters, may indicate an enlargement of the channels of the apatite structure in 
the plan $(\mathrm{x}, \mathrm{y})$. However, this structural change is not homogeneous in the whole sample as the initial apatite phase \#1 remains in the protonated sample. This could mean that the protonation was not completely achieved in the "heart" of the ceramic. Indeed, insertion of protons and oxygen ions in the structure of the material (forming "bulk species") takes place in an area close to the surface of the sample and a long step of diffusion of the defects is required to obtain homogeneous protonation $\left[{ }^{27}\right]$. The same effect can be observed in ceramics when using some sintering aid. For example, Bencan et al. showed the incorporation of Ge in $\mathrm{KNaNbO}_{3}$ ceramics, with the formation of two phases of different unit cell volumes $\left[{ }^{52}\right]$.

Table 5: Lattice parameters and unit cell volume calculated by Rietveld refinement for sample La960 before autoclave treatment $(\mathrm{GoF}=2.12, \mathrm{Rp}=6.51 \%$, $\mathrm{Rwp}=9.55 \%)$ and after protonation at $550^{\circ} \mathrm{C} / 50 \mathrm{bars} / 72 \mathrm{~h}(\mathrm{GoF}=1.20, \mathrm{Rp}=3.70 \%, \mathrm{Rwp}=4.9 \%)$.

\begin{tabular}{cccc}
\cline { 2 - 4 } & $a, b(\AA)$ & $c(\AA)$ & $V\left(\AA^{3}\right)$ \\
\hline La960_NP & $9.7204(1)$ & $7.1820(1)$ & $587.69(1)$ \\
\hline La960_72 phase \#1 & $9.7432(4)$ & $7.1864(5)$ & $590.81(4)$ \\
\hline La960_72 phase \#2 & $9.8139(3)$ & $7.1658(4)$ & $597.69(4)$ \\
\hline
\end{tabular}

The Raman spectra of the La960 samples after different durations of autoclave treatment are shown in Figure 11. Once again, it was not possible to refine the width at halfheight of the Lorentzians at $250 \mathrm{~cm}^{-1}$ (attributed to the Au mode). The shifting of the massif at $280 \mathrm{~cm}^{-1}$ to the lower wavenumbers is well visible in this figure, where the bands at 280 and $380 \mathrm{~cm}^{-1}$ (represented by orange lines) are translating to lower wavenumbers as the duration of the autoclave treatment increases. Thus, positions of Lorentzians L3 (corresponding to the band at $280 \mathrm{~cm}^{-1}$ ), and L4 and L5 (corresponding to the band at $380 \mathrm{~cm}^{-1}$ ) were refined and noted $x_{\mathrm{L} 3}, \mathrm{x}_{\mathrm{L} 4}$ and $\mathrm{x}_{\mathrm{L} 5}$ respectively in Table 6. One can note that $\mathrm{x}_{\mathrm{L} 3}, \mathrm{x}_{\mathrm{L} 4}$ and $\mathrm{x}_{\mathrm{L} 5}$ decrease from 279.93 to $276.85 \mathrm{~cm}^{-1}$, from 388.71 to $385.88 \mathrm{~cm}^{-1}$ and from 376.93 to $374.93 \mathrm{~cm}^{-1}$, respectively, while the duration of autoclave treatment rises from 0 to 408 hours. As explained in Table 1, L3 is attributed to the $\mathrm{La} 2-\mathrm{O}_{(\mathrm{SiO} 4)}$ vibration mode and $\mathrm{L} 4$ and $\mathrm{L} 5$ are attributed to the symmetric bending mode of $\mathrm{SiO}_{4}\left(v_{2}\right)$ and to the $\mathrm{La} 2-\mathrm{O}_{(\mathrm{SiO} 4)}$ vibration mode. Thus, the shift of the Lorentzians' positions to lower wavenumbers values could be due to the increase of the average length of bond $\mathrm{La}_{2}-\mathrm{O}_{(\mathrm{SiO} 4)}$. This confirms that a structural change occurs inside the large channels, which seem to be enlarged while the duration of the autoclave treatment increases. This is also in good agreement with lattice parameters 
refinements (Table 5), and seems to confirm the incorporation of protonic species into the material.

Furthermore, FWHM of Lorentzians L1 and L3, attributed to the vibrations La2$\mathrm{O}_{(\mathrm{SiO})}$, are higher in the case of samples La960 aged in autoclave compared to La960_NP. Indeed, $\mathrm{FWHM}\left(\mathrm{w}_{1}\right)$ and $\left(\mathrm{w}_{3}\right)$ are equal to 51.37 and $31.18 \mathrm{~cm}^{-1}$, respectively, for sample La960 before aging test, and are about $65-67$ and $37-39 \mathrm{~cm}^{-1}$, respectively, for samples La960 aged in autoclave. This change can be linked to the creation of a significant disorder in the La2- $\mathrm{O}_{(\mathrm{SiO} 4)}$ distances at the periphery of the large tunnels of oxyapatite, which is also consistent with the incorporation of protonic species inside the structure.

Moreover, one can notice on Figure 11 that the longer the autoclave treatment, the more visible the vibrational mode $\mathrm{Eg}$ at $440 \mathrm{~cm}^{-1}$ is. As this mode is Raman active, this could mean that the protonation process induces a symmetry change inside the large tunnels of the oxyapatite structure, leading towards ideal theoretical symmetry. This seems to confirm that a symmetry change happens inside the large channels of the oxyapatite structure during the protonation process: the symmetry may evolve towards ideal theoretical symmetry as the autoclave treatment duration increases.

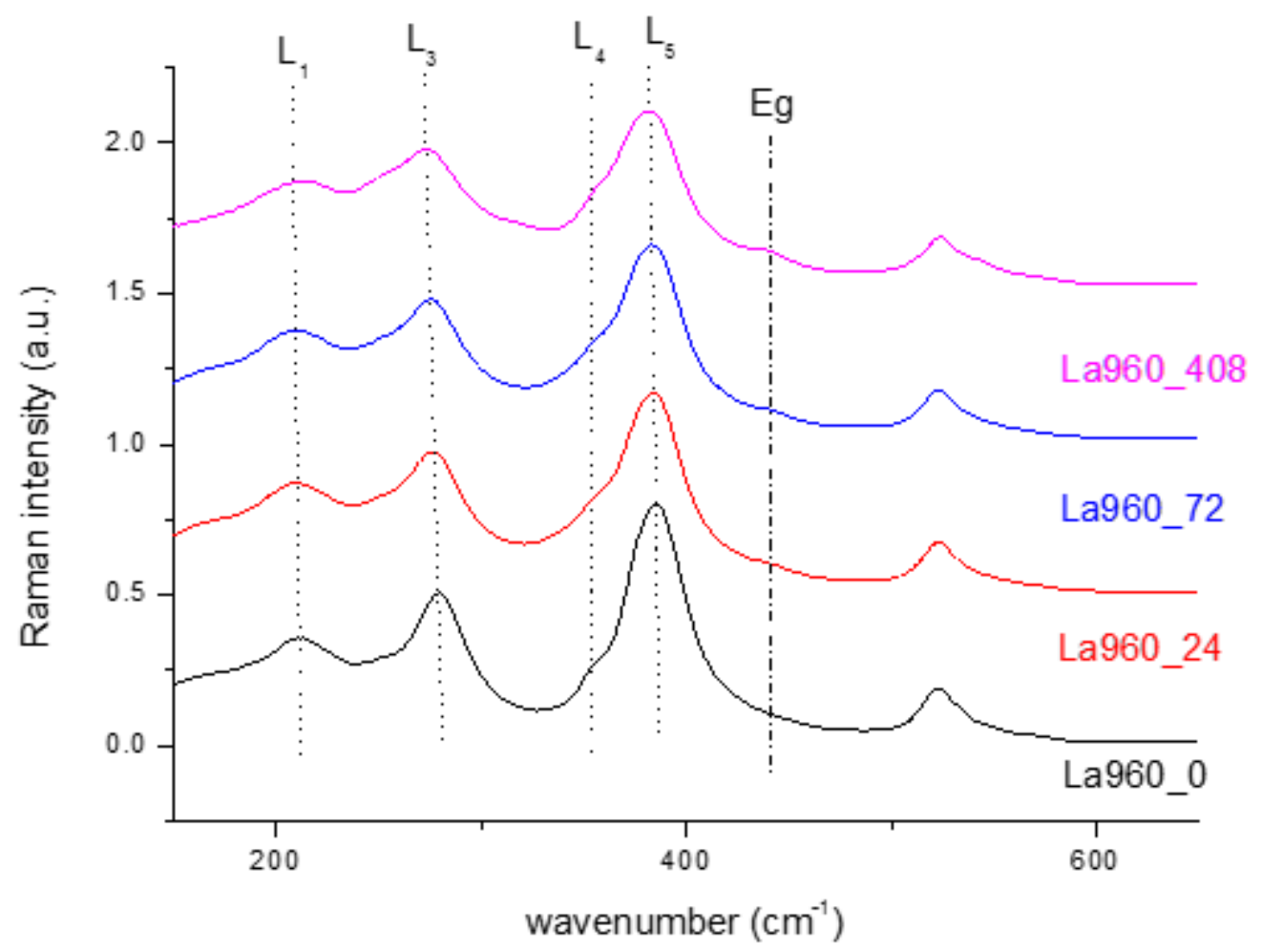

Figure 11: Raman spectra on samples La960 after autoclave treatment of 0h, 24h, 72h, and $408 \mathrm{~h}$ at $550^{\circ} \mathrm{C} / 50$ bars. 
Table 6: Refined FWHM and positions $\left(\mathrm{FWHM}\left(\mathrm{L}_{\alpha}\right)\right.$ and $\mathrm{X}_{\mathrm{L} \alpha}$ respectively, in $\left.\mathrm{cm}^{-1}\right)$ of Lorentzians $\mathrm{L} \alpha$ (with $\alpha=[1-5])$ in the case of La960 aged by autoclave treatment $\left(550^{\circ} \mathrm{C} / 50\right.$ bars/ 0h, 24h, 72h, 408h.

\begin{tabular}{cccccc} 
& & La960_NP & La960_24 & La960_72 & La960_408 \\
\hline \multirow{2}{*}{ Frequency } & $\mathrm{x}_{\text {L3 }}$ & 280 & 277 & 276 & 277 \\
$\left(\mathrm{~cm}^{-1}\right)$ & $\mathrm{x}_{\text {L4 }} \mathrm{X}_{4}$ & 389 & 386 & 386 & 386 \\
& $\mathrm{x}_{\text {L5 }}$ & 377 & 375 & 375 & 375 \\
\hline FWHM & FWHM(L 1$)$ & 51 & 65 & 65 & 67 \\
$\left(\mathrm{~cm}^{-1}\right)$ & FWHM(L3) & 31 & 37 & 40 & 37 \\
\hline
\end{tabular}

\section{Conclusion}

In this work, we have investigated for the first time the protonation of pure and dense samples of initial compositions $\mathrm{La}_{9.13}\left(\mathrm{SiO}_{4}\right)_{6} \mathrm{O}_{1.7}$ (oxygen sub-stoichiometric), $\mathrm{La}_{9.33}\left(\mathrm{SiO}_{4}\right)_{6} \mathrm{O}_{2}$ (oxygen stoichiometric), and $\mathrm{La}_{9.60}\left(\mathrm{SiO}_{4}\right)_{6} \mathrm{O}_{2.4}$ (oxygen over-stoichiometric), exposed at a temperature close to the expected operating condition $\left(550^{\circ} \mathrm{C}\right)$ under high water pressure. The effects of initial composition and protonation time were studied. It was shown that autoclave treatment induces microstructural and structural changes in the samples due to the insertion of protonic species in the volume of the material. According to thermogravimetric measurements, the over-stoichiometric composition La960 showed the highest mass gain after 84 hours of autoclave treatment at $550^{\circ} \mathrm{C}$ and 40 bars, probably due to the presence of interstitial ions leading to $O H_{i}^{\prime}$ or a combination of $O H_{O}^{\bullet}+O_{i}^{\prime \prime}$ defects, contrary to perovskite material where oxygen vacancies are favored.

Additional tests performed on composition $\mathrm{La}_{9.60}\left(\mathrm{SiO}_{4}\right)_{6} \mathrm{O}_{2.4}$ brought out that the inserted species content in oxyapatite increases when protonation time rises. SEM surface analysis of sample La960 shows the creation of striations on some grain surface after 72 hours of treatment and the increase of surface corrosion with treatment duration. After a long duration of treatments ( 408 hours at $550^{\circ} \mathrm{C} / 50$ bars), the samples are broken in several parts.

An increase of the cell volume in the $(a, b)$ plane, corresponding to an enlargement of the tunnels of the apatite structure were observed, as well as an increase of the disorder at the periphery of the tunnels. These observations confirm that protonic species were incorporated 
into the material and show that they may be located mainly inside the large tunnels of the apatite structure. The proton insertion in the structure of oxyapatite may induce the creation of active centres, which may instigate the fluorescence phenomena observed in this study.

Further investigations may be carried out in order to determine the nature of these protonic species as well as the time required to obtain homogeneous protonation for oxyapatite materials. Then, electrical characterizations of apatite in-situ autoclave coupled Raman microscopy could provide also interesting additional information to determine the effect ox protonation on the conduction properties in oxyapatites.

\section{Aknowledgments}

The authors wish to thank Julie Cornette, Richard Mayet and Pascal Munsch for their support concerning Raman spectroscopy, X-ray diffraction and autoclave experiments.

\section{References}

[1] N.Q. Minh, Solid State Ionics 174 (2004) $271-277$

$\left[{ }^{2}\right]$ O. Yamamoto, Electrochimica Acta 45 (2000) 2423 - 2435

$\left[{ }^{3}\right]$ F.M.B. Marques, V.V. Kharton, E.N. Naumovich, A.L. Shaula, A.V. Kovalevsky, A.A. Yaremchenko, Solid State Ionics 177 (2006) 1697-1703

[ $\left.{ }^{4}\right]$ S. Nakayama, T. Kageyama, H. Aono, Y. Sadaoka, J. Mater. Chem. 5 (1995) 1801-1805

$\left[{ }^{5}\right]$ S. Nakayama, M. Sakamoto, J. Eur. Ceram. Soc. 18 (1998) $1413-1418$

$\left.{ }^{6}{ }^{6}\right]$ K. Fukuda, T. Asaka, R. Hamaguchi, T. Suzuki, H. Oka, A. Berghout, E. Béchade, O. Masson, I. Julien, E. Champion, P. Thomas, Chem. Mater. 23 (2011) 5474-5483

[ $\left.{ }^{7}\right]$ K. Fukuda, T. Asaka, M. Okino, A. Berghout, E. Béchade, O. Masson, I. Julien, P. Thomas, Solid State Ionics 217 (2012) 40-45

$\left.{ }^{8}\right]$ S. Nakayama, A. Ikesue, Y. Higuchi, M. Sugawara, M. Sakamoto, J. Eur. Ceram. Soc. 33 (2013) $207-210$

[9] H. Yoshioka, J. Eur. Ceram. Soc. 90 (2007) 3099 - 3105

$\left[{ }^{10}\right]$ H. Okudera, Y. Masubuchi, S. Kikkawa, A. Yoshiasa, Solid State Ionics 176 (2005) 1473 $-1478$

$\left[{ }^{11}\right]$ K. Fukuda, T. Asaka, M. Oyabu, D. Urushihara, A. Berghout, E. Béchade, O. Masson, I. Julien, P. Thomas, Chem. Mater. 24 (2012) 4623-4631

$\left.{ }^{12}\right]$ T. Iwata, K. Fukuda, E. Béchade, O. Masson, I. Julien, E. Champion and P. Thomas, Solid State Ionics 178, (2007), 1523-1529 
$\left[{ }^{13}\right]$ J.R. Tolchard, M.S. Islam, P.R. Slater, J. Mater. Chem. 13 (2003) 1956-1961

$\left[{ }^{14}\right]$ E. Béchade, O. Masson, T. Iwata, I. Julien, K. Fukuda, P. Thomas, E. Champion, Chem. Mater. 21 (2009) 2508-2517

$\left[{ }^{15}\right]$ S. Nakayama, Y. Higuchi, M. Sugawara, A. Makiya, K. Uematsu, M. Sakamoto, Ceram. Int. 40 (2014) 1221-1224

$\left[{ }^{16}\right]$ K. Fukuda, T. Asaka, S. Hara, M. Oyabu, A. Berghout, E. Béchade, O. Masson, I. Julien, P. Thomas, Chem. Mater. 25 (2013) 2154-2162

$\left[{ }^{17}\right]$ E. Béchade, Thesis, University of Limoges (2008)

$\left[{ }^{18}\right]$ L. León-Reina, J.M. Porras-Vázquez, E.R. Losilla, M.A.G. Aranda, J. Solid State Chem. 180 (2007) $1250-1258$

$\left[{ }^{19}\right]$ A. Orera, P.R. Slater, Solid State Ionics 181 (2010) $110-114$

$\left[{ }^{20}\right]$ P.M. Panchmatia, A. Orera, E. Kendrick, J.V. Hanna, M.E. Smith, P.R. Slater, M.S. Islam, J. Mater. Chem. 20 (2010) 2766-2772

$\left[{ }^{21}\right]$ J.A. Kilner, J. Druce and T. Ishihara, High-Temperature Solid Oxide Fuel Cells for the 21st Century: Fundamentals, Design and Applications: Second Edition, November 16 (2015), 85-132 (Book Chapter)

$\left.{ }^{22}\right]$ T. Norby, J. Chem. Eng. Jpn. 40, (2007), 1166-1171

$\left[{ }^{23}\right]$ D.G. Thomas and J.J Lander, J. Chem. Phys.25 (1956), 1136-1142

$\left[{ }^{24}\right]$ A. Slodczyk, P. Colomban, S. Willemin, O. Lacroix, B. Sala, J. Raman Spectrosc. 40 (2009) 513-521

$\left[{ }^{25}\right]$ P. Colomban, A. Slodczyk, D. Lamago, G. Andre, O. Zaafrani, O. Lacroix, S. Willemin, B. Sala, J. Phys. Soc. Jpn. 79 (2010) 1-6

$\left[{ }^{26}\right]$ P. Colomban, A. Slodczyk, Eur. Phys. J. Special Topics 213 (2012) 171-193

$\left[{ }^{27}\right]$ P. Colomban, O. Zaafrani, A. Slodczyk, Membranes 2 (2012) 493-509

$\left[{ }^{28}\right]$ A. Slodczyk, O. Zaafrani, M.D. Sharp, J.A. Kilner, B. Dabrowski, O. Lacroix, P. Colomban, Membranes 3 (2013) 311-330

$\left[{ }^{29}\right]$ A. Slodczyk, M.D. Sharp, S. Upasen, P. Colomban, J.A. Kilner, Solid State Ionics 262 (2014) 870-874

$\left[{ }^{30}\right]$ Y. Larring, C. Vigen, F. Ahouanto, M-L. Fontaine, T. Peters, J. B. Smith, T. Norby and Rune Bredesen, Membranes 2 (2012) 665-686

$\left[{ }^{31}\right]$ H. Iwahara, Solid State Ionics 86-88 (1996) 9-15 
$\left[{ }^{32}\right]$ K.J. de Vries, Solid State Ionics 100 (1997) 193 - 200

$\left[{ }^{33}\right]$ P. Colomban, Annales de Chimie - Science Des Matériaux 24 (1999) 1-18

$\left[{ }^{34}\right]$ A.S. Nowick, Y. Du, Solid State Ionics 77 (1995) 137 - 146

$\left[{ }^{35}\right]$ A.S. Nowick, A.V. Vaysleyb, Solid State Ionics 97 (1997) 17 - 26

$\left[{ }^{36}\right]$ K.D. Kreuer, Annu. Rev. Mater. Res. 33 (2003) 333-359

$\left[{ }^{37}\right]$ S. Deng and Y. Zhang, Phys. Status Solidi B, 253 (2016) 1688-1696

$\left[{ }^{38}\right]$ T. Norby, M. Widerøe, R. Gløckner and Y. Larring, Dalton Trans.19, (2004), 3012-3018

$\left.{ }^{39}\right]$ P. Colomban, C. Tran, O. Zaafrani, A. Slodczyk, J. Raman Spectrosc. 44 (2013) 312-320

$\left[{ }^{40}\right]$ P. Colomban, Fuel Cells 13 (2013) 6-18

$\left.{ }^{41}\right]$ E. Rodríguez-Reyna, A.F. Fuentes, M. MacZka, J. Hanuza, K. Boulahya, U. Amador, Solid State Sci. 8 (2006) 168-177

$\left.{ }^{42}\right]$ M. Smirnov, S. Sukhomlinov, A. Mirgorodsky, O. Masson, E. Béchade, M. Colas, T. Merle-Méjean, I. Julien, P. Thomas, J. Raman Spectrosc. 41 (2010) 1700-1707

$\left[{ }^{43}\right]$ A. Pons, J. Jouin, E. Béchade, I. Julien, O. Masson, P.M. Geffroy, R. Mayet, P. Thomas, K. Fukuda, I. Kagomiya, Solid State Sci. 38 (2014) 150-155

$\left[{ }^{44}\right]$ A. Pons, Thesis, University of Limoges (2014)

$\left[{ }^{45}\right]$ H.M. Rietveld, J. Appl. Crystallogr. 2 (1969) 65-71

$\left[{ }^{46}\right]$ JANA2006 Software. Download website: http://jana.fzu.cz/

$\left[{ }^{47}\right]$ Focus, Software Utility for the Creation of Optical Function, Domingos DE SOUSA MENESES, CEMHTI, UPR-CNRS 3079, Orléans. Download website: http://crmht.cnrsorleans.fr/pot/software/focus.html

$\left[{ }^{48}\right]$ E. Béchade, I. Julien, T. Iwata, O. Masson, P. Thomas, E. Champion, K. Fukuda, J. Eur. Ceram. Soc. 28 (2008) 2717-2724

$\left[{ }^{49}\right]$ J. D. Pasteris, B. Wopenka, J. J. Freeman, K. Rogers, E. Valsami-Jones, J. A. M. van der Houwen, et M. J. Silva, Biomaterials 25 (2004) 229-238

$\left[{ }^{50}\right]$ B. Sala, F. Grasset, O. Lacroix, A. Sirat, K. Rahmouni, M. Keddam, H. Takenouti, D. Goeuriot, B. Bendjeriou, Ph. Colomban, A. van der Lee, J.G. Sanchez, WO2013053858 A1 (18/04/2013) Google Patents, France, 2013

$\left[{ }^{51}\right]$ T. Iwata, E. Béchade, K. Fukuda, O. Masson, I. Julien, E. Champion, P. Thomas, J. Am. Ceram. Soc. 91 (2008) 3714-3720

$\left[{ }^{52}\right]$ A. Bencan, J. Bernard, J. Tellier, B. Malic and M. Kosec, Microsc. Microanal. 15 (2009) 786-787 